\title{
Absence of distal interphalangeal creases of fingers with flexion limitation
}

\author{
K. FRIED and G. MUNDEL \\ Department of Genetics and Paediatrics, Asaf Harofe Government Hospital, Tel-Aviv University Medical School, \\ Zerifin, Israel
}

\begin{abstract}
Summary. An Ashkenazi Jewish family is described, in which absence of distal interphalangeal creases of fingers with flexion limitation is transmitted through 4 generations with 8 affected individuals. The malformation is caused by an autosomal dominant gene with full penetrance and variable expressivity, and causes only little inconvenience. In one case the joints were normal on radiological examination. The malformation was not associated with any other anomaly except in the propositus who was referred because of profound mental retardation and cerebral palsy. This association is probably fortuitous as the other affected members were of above average intelligence. We were unable to find any report on this anomaly without associated malformations.
\end{abstract}

Absence of the distal crease of a finger is often associated with a flexion deformity. A single crease on the fifth finger is found in several syndromes (both chromosomal and mendelian) in association with deformity of the middle phalanx and extremely rarely in otherwise normal individuals. The present family is reported because we were unable to find any reference to autosomal dominant absence of distal interphalangeal creases of fingers with limitation of flexion but without any other anomaly.

\section{The family}

The propositus (IV.1, Fig. 1) was the first child of Ashkenazi Jewish parents. He was born in June 1968 after a full-term pregnancy which was complicated by slight bleeding in the first trimester. The mother was 27 years old and the father was 29 at the birth of the propositus. The newborn, whose birthweight was $3 \mathrm{~kg}$, had a head circumference of $32 \mathrm{~cm}$, was hypertonic, and spontaneous clonic movements of the upper extremities were noted soon after birth. His development was profoundly retarded. At the age of 6 years he had generalized spasticity, with contracture of the knees. He was unable to walk or talk. He had an unusual facies with large low set ears and confluent eyebrows. His eyes had a slight mongoloid slant and his nose was short with narrow nares. His head circumference was $46 \mathrm{~cm}$. The karyotype was normal.
An incidental finding in the propositus was the familial trait of absence of distal interphalangeal creases of fingers. This trait was known to be present in the father III.1 and other normal members of the family. The trait manifested in the propositus by an almost complete absence of the distal interphalangeal creases of fingers II, III, IV, and V on the volar side and complete absence of those creases on the dorsal side, on both hands. The nails were normal.

The trait was reported to be traced to the deceased paternal great grandmother I.1. Three of her children inherited the trait. II.1 the paternal grandfather of the propositus, a school teacher, was found on examination at age 60 to have an almost complete absence of the distal creases of fingers II, III, IV, and V on the volar

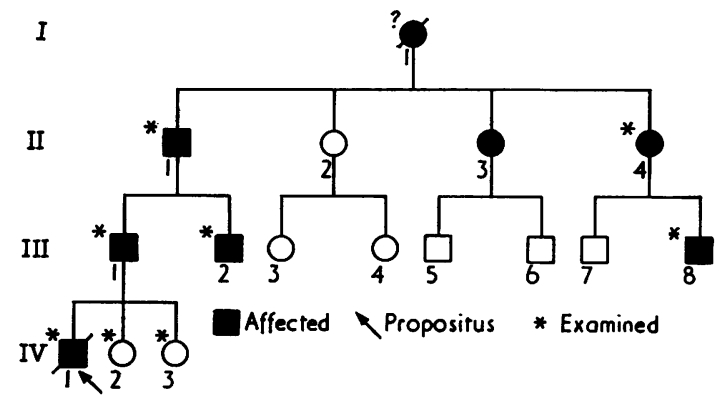

Fig. 1. Family pedigree.

Received 17 January 1975. 


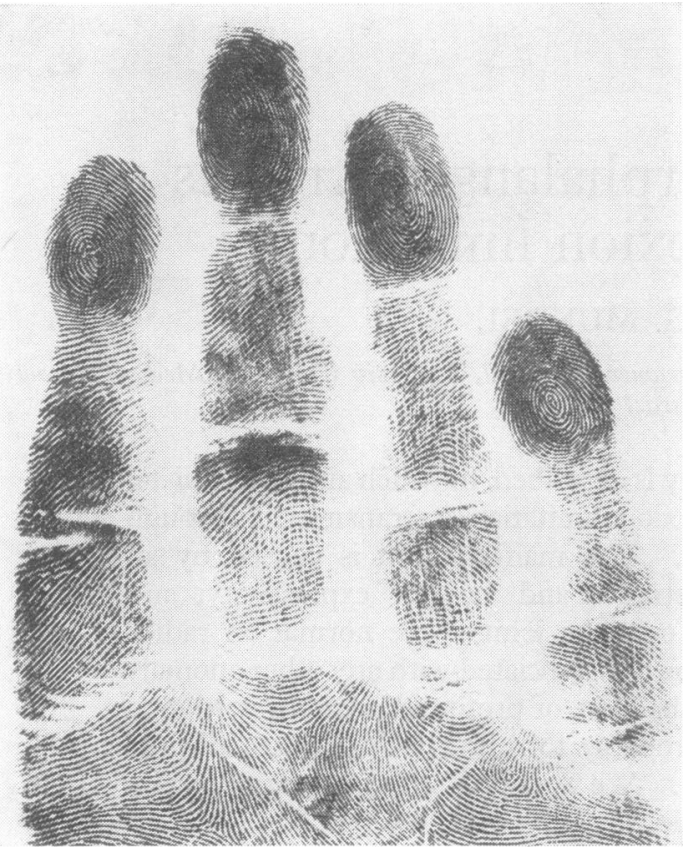

FIG. 2. Fingerprints of right hand (III.1). side and complete absence of those creases on the dorsal side. This finding was bilateral. The fifth finger was incurved only on the right hand and caused a slight indentation of the fourth finger. His only complaint was that he was unable to play the violin because of the inability to flex the distal interphalangeal joints of fingers II, III, IV, and V.

II.3 was reported to have the trait but could not be examined as she lives abroad. II.4 was examined at the age of 42. She had complete bilateral absence of the distal creases of the fifth finger and partial absence of those creases on fingers II, III, and IV on the volar side. She had no distal creases on the dorsal side of fingers II, III, IV, and V. She was able to flex the interphalangeal joints.

III.1 is the father of the propositus and is a university graduate. He is now 35 years old and is a colonel in the army. He has limitation of flexion of the distal interphalangeal joints II, III, IV, and V and absence of the distal creases on the dorsal side, while on the volar surface the creases were completely absent on fingers II and V they were noticeable on fingers III and IV (Fig. 2). In spite of the limitation of flexion, the joint appears to be completely normal (Fig. 3), on radiological examination.

III.2 is a 26-year-old psychology graduate student. He has absence of the distal crease of finger $\mathrm{V}$ on the volar surface on the right hand (Fig. 4), while on the dorsal surface the creases are absent on both finger II

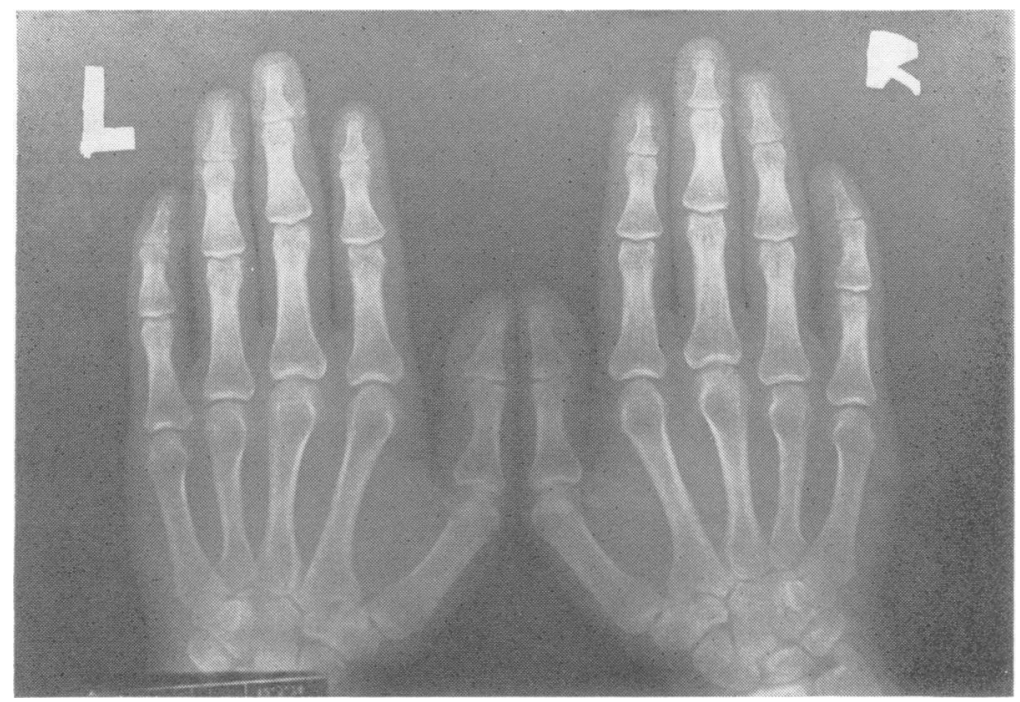

FIG. 3. Normal interphalangeal joints on $x$-ray (III.1). Note incurved fifth finger. 


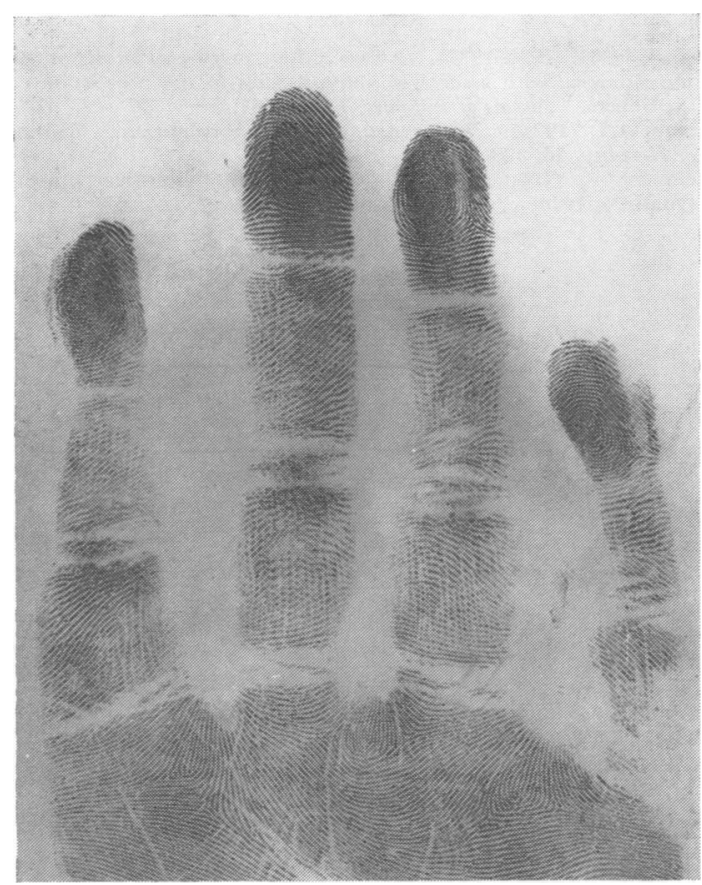

FIG. 4. Fingerprints of right hand (III.2).

and finger $\mathrm{V}$, and he is unable to flex the distal joints of those two fingers. The left hand is similarly affected except that the distal crease on the volar surface of finger II is also absent.

III. 8 is a 13-year-old secondary school student and seems to be the most extensively affected person among those examined. His condition is bilaterally symmetrical. There is complete absence of the distal creases of the fingers and thumbs on both the volar and dorsal surfaces (Fig. 5) and bilateral clinondactyly of the fifth finger. There is limitation of flexion on the distal interphalangeal joint of the fingers.

\section{Discussion}

The minor malformation in this family is caused by an autosomal dominant gene with complete penetrance and variable expressivity. The affection is not completely symmetrical and often there is a slight degree of difference between the right and left hand. As the ability to flex the distal interphalangeal joints is not essential for a firm grip, and as there is no flexion deformity, this limitation may go unnoticed until a skill that is dependent on this ability, such as playing the violin, is attempted. In at least one case (III.1) with limitation of flexion, the interphalangeal joints were normal on radiological examination. This suggests that the limitation may be the result of a minor muscular or neuromuscular abnormality. The association in the propositus with profound mental retardation is probably fortuitous as the other affected members were of above average intelligence.

The condition described in the present family has some resemblance to a previously described family with distal symphalangism (Inman, 1924; Steinberg and Reynolds, 1948) and also to another family reported by Daniel (1936-1937). Steinberg and Reynolds published the $x$-rays of the hands of $3-$ year-old twins who show no evidence of fusion of the distal and middle phalanges, and they state: 'It is likely that such fusion will occur at a later age.' Their comment is probably based on the fact that the other affected members of that family had such fusion. In the present report no affected member had such fusion as evidenced by the $x$-ray in one adult (Fig. 3) and the presence of at least some passive movement in all the distal interphalangeal joints in all the examined affected persons (4 adults and 2 children). Though it is theoretically possible

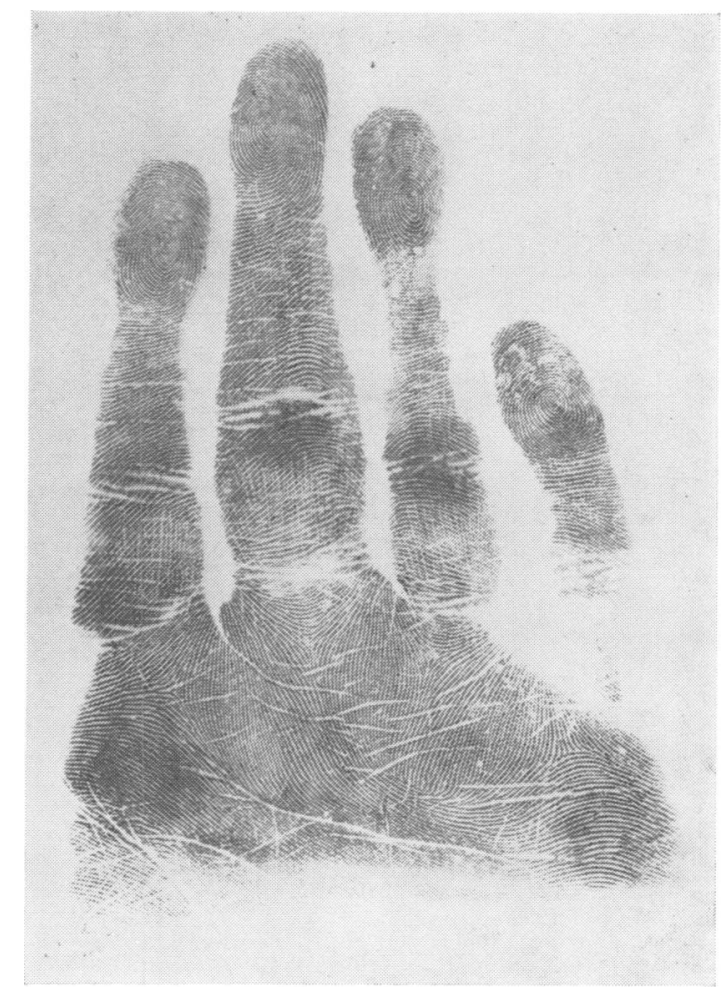

FIG. 5. Fingerprints of right hand (III.8). 
that the same gene with variable expressivity will cause in one family always or almost always bone fusion while in another it will cause only flexion limitation without bone fusion, it seems more likely that the cause of the difference is a different dominant gene.
REFERENCES

Daniel, G. H. (1936-1937). A case of hereditary anarthrosis of the index finger, with associated abnormalities in the proportion of the fingers. Annals of Eugenics, 7, 281-297.

Inman, O. L. (1924). Four generations of symphalangism. Fournal of Heredity, 15, 329-334.

Steinberg, A. G. and Reynolds, E. L. (1948). Further data on symphalangism. Fournal of Heredity,139, 23-27. 